\title{
Breast Implants for Graduation: A Sociological Examination of Daughter and Mother Narratives
}

\author{
Lori Ann Fowler ${ }^{1}$, Ami R. Moore ${ }^{2}$ \\ ${ }^{1} \mathrm{NE}$ Campus, Tarrant County College, Hurst, USA \\ ${ }^{2}$ Department of Sociology, University of North Texas, Denton, USA \\ Email: lori.fowler@tccd.edu, ami.moore@unt.edu
}

Received October $5^{\text {th }}$, 2011; revised November $6^{\text {th }}$, 2011; accepted December $6^{\text {th }}, 2011$

\begin{abstract}
The purpose of this research is to examine through sociological theories how young women and their parents make sense of the desire, attainment, and gifting of breast implants for graduation. A qualitative study of 10 high school graduates and their mothers was conducted in the state of Texas, USA, in order to understand why the daughters asked for implants as a graduation gift and why their parents, especially, mothers paid for them. Four theoretical paradigms provided a better understanding of the gifting and receiving of breast implants for graduation: symbolic interaction theory, the social construction of reality, reference group theory, and conspicuous consumption. This study shows that gifting and receiving implants for graduation is primarily motivated by both personal feelings of physical inadequacy and sociocultural representation of beauty.
\end{abstract}

Keywords: Breast Implants; Graduation; Adolescents; Sociological Theories; Texas

\section{Introduction}

Research has shown that of all age groups, teenagers are the most likely to be dissatisfied with their appearance. In a longitudinal study of girls and boys ages 11,13, 15 and 18, Raustevon Wright (1989) found that satisfaction with one's body was reported highest at age 18, with males more satisfied than females at all age levels. However, those who developed secondary sex characteristics after their peers were more satisfied with their bodies than early maturers who developed secondary sex characteristics before their peers.

Under pressure to look good and gain admiration from peers, teens are now seeking breast enlargements at unprecedented levels. Popular, well-endowed teen idols like Britney Spears and Lindsay Lohan have made some girls dislike their own bodies (More Girls Getting Implants, 2004: p. 5). Thus, young women are seeking breast augmentation at younger ages (ASAPS, 2004). Also, since the costs of getting plastic surgery have gone down and technology is speeding up, these procedures have become more viable to teens (Austin, 2000). The message is that kids can, with enough money, change their bodies for the better.

The numbers of teens that seek cosmetic surgeries nearly doubled in just a few years. In fact, between 1996 and 1998, teen cosmetic surgery rose from 13,699 to 24,623 (Austin, 2000). However, in 2003, almost 331,886 teens 18 or younger had some kind of cosmetic surgery procedure, a $48 \%$ increase over 2002 (Kelley, 2003). Breast augmentation and liposuction are some of the areas where demand has been on the rise. The number of teenage breast implants and liposuctions rose by 562\% between 1994 and 2001 (Beyond Botox, p. 61).

Several reasons have been offered as to the unprecedented growth in teen cosmetic surgery. Some believe that teens view augmentation surgery as a quick fix. For some girls, augmentation may be considered a rite of passage or a link to a new iden- tity. The young girls receiving the implants for graduation claim they ask for them because they are about to embark on a lifestyle change-leaving high-school and entering the college atmosphere (More Girls Getting Implants, p. 4). As a report by ABC News anchor John Stossel reveals (2005), the implants allow some to feel more confident, more adult, and happy.

While some parents believe that helping daughters get breast augmentation improves the psychological well-being of the girls, mothers, especially report that they pay for breast implants in order to boost their daughter's self-esteem and make them happy (McKenzie, 2006). In some instances, parents who have the money to afford the implants cannot bear for their children to be unhappy (ABC News, 2005). Furthermore, mothers who have had breast surgery themselves seem more likely to allow their daughters to undergo such procedures. The reported boost to their own self-esteem becomes a gift they can then pass on to their next of kin. There are cases where mothers and daughters have the procedure done together. Indeed, it has been found that in $25 \%$ of cases, mothers and daughters undergo surgery at the same time (DeNoon, 2003).

The phenomenon of giving implants for graduation is taking off across the country, but doctors say it is especially popular in Texas and California (More Girls Getting Implants, 2004: p. 5). Some parents believe that "it's cheaper than a car and better than a fountain pen” (Farrell, 2004: p. 2).

This study, like most body image research, focuses on women alone for several reasons. There is general agreement that the pressure to appear attractive is more pronounced for women than for men (La Voie, 2000; Bulik \& Kendler, 2000; Holzgang, 2000). In addition, their self-concepts are highly affected by television and print media (Rabak-Wegener, Eickhoff, \& Vance, 1998). Research shows that women are less satisfied with their bodies than men (Harrison, 2003). Additionally, women encounter more prejudice when they are considered overweight, they are more likely to diet, have plastic 
surgery, and have problematic relationships with food (Orbach, 1993). Thus, this research uses a narrative approach to investigate reasons why some young women ask for breast implants for graduation, and why parent(s) pay for such procedures.

\section{Theoretical Background}

\section{Symbolic Interaction and Cosmetic Surgery}

The symbolic interaction perspective is a valuable tool in analyzing human behavior at the microlevel (Blumer, 1969). Symbolic interaction theorists purport that behavior originates within the constructs of the mind. The world humans inhabit is seen as a social construction, a product of our ability to think and express our thoughts symbolically. Things we recognize as being part of our society may simply be products of our own mind. Society is therefore an elaborate fiction we create in order to help make sense of our relationships and the world around us.

Symbolic interaction theory may serve as a basis for understanding how women interpret their own beauty and respond to the environments in which they live. The internalization of media images and a woman's perception of her own beauty may influence whether she chooses or refuses cosmetic surgery.

Internalization is a process through which people come to identify parts of the culture as themselves, especially in relation to norms that guide decisions about appearances and behavior. Internalization is a crucial element that may lead some people to regulate their own appearance in accordance with accepted forms, i.e., those displayed in the media.

Further, symbolic interactionists such as Charles Horton Cooley (1964), George Herbert Mead (1934), W. I. Thomas (1923), and Erving Goffman (1959) all described thought processes that might motivate women to create good impressions, to put on good performances, and to reflect upon their own body image. Cooley described the self-concept as an entity formed through social interaction. His concept of the looking-glass self is one derived from the outside world. According to Cooley, one's body image reflection may involve three principal elements: the imagination of our appearance to the other person; the imagination of his or her judgment of that appearance; and some sort of self-feeling, such as pride or mortification in return. The imagined judgment is quite essential. The thing that moves us to pride or shame is not the mere mechanical reflection of ourselves, but an imputed sentiment, the imagined effect of this reflection upon another's mind. We often imagine, and in imagining, share the judgments of the other mind (Cooley, 1902).

Cooley stated that the social self is simply an idea drawn from society. The person looks to others for a sense of how he or she is perceived and comes to judge the self accordingly. The self-concept, once formed, explains motivations for behavior. Also, Cooley believed that internal thinking involves imaginary conversation carried on silently within one's mind. The assumption may then be made that one's own level of attractiveness is based on the interpretation of other's perceptions. Consequently, one who feels unattractive to others or to oneself and has the financial means to change her appearance may have private mental conversations leading to cosmetic surgery (Didie \& Sarwer, 2003).

Expanding on Cooley's notion of the "looking-glass self", Mead examined the parts of oneself that emerge in different social situations. According to Mead, after one has interacted with other people over time, a "me" emerges. This "me" is how a person would imagine and describe her own behavior if she were to role-play in various situations (Mead, 1934). Mead believed that our concept of "self" is derived from social experience. The "me" or self-image, emerges after interaction with others. The "me" can become the imaginary person that we act out in various social settings in our minds to role-play, and to try out certain things before we actually do them in real life. In a way, this "me" might represent the voice that talks to women in the mirror, "If I only had breasts that were up here, then I'd be happy", or "If my thighs were only this thin, then I would be..." Before a woman undergoes such surgery, she is likely to play out in her mind what her life will be like when she gains the "perfect body part" that she believes she is currently lacking (Sarwer, Magee, \& Clark, 2004). Indeed, while Cooley's looking glass allows for a woman to think about cosmetic surgery; Mead's role-playing practices explain how she pretends in her new body.

Other theorists that give insights as to why some women get plastic surgery are W. I. Thomas (1923) and Erving Goffman (1959). Thomas believed that within everyday life, the way one defines a situation will not only influence the present, but the entire personality of the individual. If, for instance, a certain behavior becomes defined as prestigious, and is internalized, then this behavior may be what people desire. While Goffman stated that humans go through life as though they were performing on stage. On the backstage, our true self emerges but on the front stage, we try to manage the impression we want people to have of us. Consequently, behaviors that become identified as prestigious are used as tools, in the front stage especially, to gain status and create specific impressions in the minds of others (Goffman, 1959). In today's society, the beautiful woman and her behavior have become a prestigious status symbol (Synnott, 1989).

Further, advertising and media icons strive to pressure consumers, especially women, to reconsider their appearances. As stated by Kilbourne (1994), if a "look" is portrayed as the ideal in society, women often choose that prestigious, beautiful image even when it comes at a costly price. Women who internalize media images as real may be more likely to choose cosmetic surgery in order to attain prestige, whereas women who view media icons as unattainable, false representations may be less likely to undergo elective procedures (Harrison, 2003).

It is important to note that the American socialization process is influenced by the media, thus our meanings and interpretations of beauty are influenced as well (Harrison, 2003). We have been socialized to know what is considered "beautiful" or "ideal” (Kilbourne, 1994). When we cross paths with either the beautiful or the unattractive, interpretations of physical symbols may drive the way in which we view the people we see, and ourselves. As reported by Didie and Sarwer (2003), Western culture, media influence, and symbolic interaction may result in body dissatisfaction, thus motivating some women to undergo cosmetic surgery procedures.

\section{Social Construction of Reality Theory and Cosmetic Surgery}

The social construction of reality represents the social processes by which humans collectively construct, interpret and assign meaning to their actions, institutions, roles, and events 
(Berger \& Luckmann, 1966). The human body itself may be seen as a social construct, a means of social expression or performance by which our identity and value is created, tested, and validated (Sile, 1981). For instance, Simone de Beauvoir clearly expressed this idea when she stated: "One is not born, but rather becomes, a woman...; it is civilization as a whole that produces this creature which is described as feminine" (1952: p. 267). In fact, in social interaction throughout life, humans learn others' expectations and act and react in accordance, maintaining the gender order (Lorber, 1994). Gender is constantly created and re-created out of human interaction and depends on everyone constantly "doing gender".

As a process, gender construction creates the social differences that define a "woman" and "man". In daily encounters, humans produce gender, behaving in ways they learned were appropriate. In The Politics of Women's Bodies: Sexuality, Appearance, and Behavior, Rose Weitz demonstrates how societal standards of beauty affect women's lives (1999). Weitz states that once ideas about ideal body types become accepted and generated by the media, they can serve as powerful-and political-tools for controlling women's appearance, sexuality, and behavior. Media depictions of ideal body types reflect and reinforce the powerlessness that many women have over their own bodies. Social constructions often are powerful enough that women augment their breast size with silicone and reconstruct their faces with cosmetic surgery to conform to cultural ideals of feminine beauty. As stated by West \& Zimmerman (1987), when women change their own body structures consistently, these gender constructs are rendered legitimate.

\section{Reference Group Theory and Cosmetic Surgery}

The basic premise of reference group theory is that much of human behavior is driven by reference groups, or those groups that influence the attitudes and behavior of individuals (Dawson \& Chatman, 2001). People often take the standards of significant others as a basis for making self-appraisals and comparisons (Hyman \& Singer, 1968). Reference groups give individuals a basis for comparing themselves to others and are often used as a sort of yardstick allowing one to measure how they "stack up" relevant to some standard.

According to research, how people stack up against the group with which they most often compare themselves has an enormous impact on their behavior. Schor (1998) analyzed consumerism and television, and found that the more TV a person watches, the more he or she spends. Shrum, Burroughs, and Rindfleisch (2005) found that the more people watch dramatic TV shows, the more they think American households have tennis courts, private planes, convertibles, cell phones, maids, and swimming pools. These same viewers overestimate the proportion of the population who are millionaires, have had cosmetic surgery, and belong to private gyms. Thus, it is safe to conclude that media, especially TV has significant impacts on its viewers who not only tend to compare themselves to the stars and icons that are portrayed in the different shows but also think everyone else looks just like the stars and icons excepts themselves.

In general, individuals seek membership into certain groups because of the groups' perceived status and the benefits gained from belonging to such groups (Dawson \& Chatman, 2001). Reference groups possess power through their ability to influence individuals who desire to become members. A woman's perception of her own appearance may be driven by comparisons with women in the media, or women others view as "beautiful". Women may seek affiliation with women viewed as beautiful because they are depicted as having desirable social status. Some women may choose beautiful women as a reference group and ultimately undergo surgery in an effort to feel part of a more favored group.

\section{Conspicuous Consumption Theory and Cosmetic Surgery}

In Veblen's classic work, The Theory of the Leisure Class, he states that status is determined by displaying wealth through acts of conspicuous consumption (1899). Conspicuous consumption involves the acquisition and display of items that attract attention to one's wealth or suggest that one is wealthy. It is an economic, cultural, and social process that reflects the opportunities and constraints within a society (Zukin \& Maguire, 2004). Consumer goods are often used by socio-economic classes to differentiate their status from others. These goods serve as symbolic cues that signal levels of prestige.

The Veblen thesis proposes that the rich set standards that the rest follow. For example, the middle class may emulate the upper class by purchasing fine articles of clothing, and the lower class may emulate the middle class by driving a fine automobile in an effort to elevate perceived status. Americans are engaged in an intensifying "national shopping spree" rooted in competitive emulation-keeping up with the Joneses on a manic scale (Schor, 1998). The wealthy have set spending precedents for everyone else.

The eccentricities of the rich have a purpose, to reaffirm their status as members of the leisure class and to display power (Veblen, 1899). According to Veblen, the display of power was external in pre-industrial society. It was easy to "see" who the powerful were in feudal society because they commanded large armies and ruled over segments of society while living in castles (Carolan, 2005). There was no need to speak of conspicuous consumption because all consumption was a display of power. Individuals today, however, no longer rule over peasant classes. Consumption is now something done by all. As such, status is displayed in other ways. We are no longer content with merely surrounding ourselves with "nice things". But instead, as reported by Carolan (2005), we now strive to become the "nice thing" itself-to literally embody conspicuous consumption.

Within American consumer society, the youthful and attractive body has become a status cue. Beauty has come to represent the good life- - viewed as a display of high social status and prestige (Sile, 1981). A fit, firm, exercised, and well-regulated body has come to symbolize personal triumph over impulse. A body in control over itself has come to represent a body in control of the world around it (Carolan, 2005). The opportunity for one to control the world around them is marketed heavily in the West (Davis, 2003). Cosmetic surgery is a form of consumption, and a very conspicuous one at that (Carolan, 2005). What could be more conspicuous than something which alters your body, the very thing you take with you everywhere?

This study uses narratives to sociologically examine the reasons that motivate on one hand daughters to ask for breast augmentation for graduation and on the other hand parents to pay for such procedure. 


\section{Methods}

The study used a qualitative design in order to capture the experiences and decision making processes of those giving and receiving breast implants for graduation. A narrative approach is used because narratives are discourse with clear sequential order that connect events in a meaningful way (Hinchman \& Hinchman, 1997). The chronology of events distinguishes it from mere description by linking a prior choice or event to a subsequent one. Also, narratives empower research participants and allow them to determine the most important themes in an area of research. The telling of a personal narrative aids in the development of one's sense of self (Mishler, 1995).

Further, as stated by Ferber (2000), narratives do not merely reflect experience, they give meaning to it. In the re-telling of a life experience in the form of a narrative, an individual is forced to reflect on those experiences most readily remembered. It is this process of making sense out of experience that makes narratives different from and better than structured interviews. Thus to gain a better understanding of the world of women (daughters and mothers) who underwent or paid for breast augmentation surgery, using narrative will shift responsibility to the subjects (Chase, 1995).

\section{Recruitment Procedure and Data Collection}

Participants were selected by means of purposive sampling. Daughters who have received breast implants for graduation and their mothers were asked to participate in the study. Only mothers were asked to participate because they too may have undergone breast augmentation. For mothers who had not undergone breast augmentation surgery themselves, perhaps the gift was motivated by their own unmet desires.

A total of twenty interviews were conducted and digitally recorded by the first author from June to September 2008. The daughters and mothers were all Texas residents. Eight daughters had received breast implants as a graduation gift from their parent(s) and two from their grandmother(s). The participants lived in nine cities in North Central Texas. Several of the daughters were living away on college campuses and were interviewed while home visiting family members. All interviews were conducted in accordance with the University of North Texas Institutional Review Board (IRB) policies.

\section{Data Analysis}

The interviews were transcribed verbatim. Both authors independently read the transcripts several times in order to be 'immersed' in the text. Each author separately analyzed the data. Recurrent themes, phrases, and explanations were classified and inductively analyzed. Some patterns emerged from the data independently of predetermined analytical approaches (Patton, 1990). The authors then examined the relationships between categories. They had frequent meetings whereby categories were operationalized and consensus was reached.

\section{Sample}

Participants ranged in age from 19 to 61, with a mean age of 50 for the mothers and 21 for the daughters. Five mothers had undergone breast augmentation themselves. Of the ten mothers, six were married and four were divorced. Of the ten daughters, only one was married, all others were single. Only one of the daughters had children, but all others planned to in the future. Sixteen of the participants self-identified as Caucasian, and four as Hispanic. Both mothers and daughters were at least high school graduates. Also, two of the daughters did not hold a paid job while the rest were employed with incomes ranging from $\$ 100$ to $\$ 3600$ per month. Two of the daughters reported being upper-class, three being upper-middle, and five being middle class. However, one mother classified herself as upper-class, five as upper-middle, and four as middle-class. Using the tax appraisal database, primary residence property values ranged from $\$ 91,900$ to $\$ 235,400$.

\section{Findings}

Several behaviors and practices of both daughters and mothers can be explained by symbolic interaction perspective. Most of the daughters in the narratives told stories of "faking" the appearance of large breasts prior to implant surgery. To achieve the desired look, they used heavy cotton padding, water bras, or multiple bras. Some sewed shoulder pads into their bra cups; others sewed darts into their shirts. These secret efforts to manage impressions were hidden in some cases from friends and boyfriends.

Evidence of a metaphorical backstage to front stage transition was exemplified in Annie ${ }^{1 \text { 's }}$ description of her costume change:

I mean people would see me, and they would think I had boobs just cuz of the bra; but, I really didn't.

In accordance with Goffman's theory, Sheryl's efforts made backstage allowed her to believe she was perceived as wellendowed:

All through high-school I wore padded bras, and I made it look realistic, and then they're like, “Oh, I didn't even know you needed surgery".

From removable external padding to surgical internal padding, the transition was undetectable according to some women. One of the participant's mother stated:

Traci covered her issue that she did not have babushkas (breasts) well. She dressed, she fixed, you would never know.

Further evidence of faking out the audience is seen in Sandy's statement regarding her daughter, Jane:

You know I think a lot of people don't know, just because we did it in between high-school and college. So unless you knew her when you went to high-school, there's really not a change.

Additional support for Goffman's claim that one wishes to convince their audience that they are valuable to society, i.e., well-endowed, is found in Sheila's description of how Stephanie has convinced her audience that she has always been wellendowed:

...The people she is dealing with now, unless she came right out and told them, they have no clue she had her boobs enlarged.

All of these women made efforts to conceal their true appearance in the backstage to manage how they appeared on the front stage and to create the desired impression. With the growing availability of breast augmentation surgery, more and more women now have the option to permanently alter their breast sizes to change the body they display to audience members.

Another symbolic interactionist theory, Cooley’s looking-

${ }^{1}$ Names are pseudonyms. 
glass self, can also explain some of the behaviors found in this study. According to Cooley, one's body image reflection may involve three principal elements: the imagination of one's appearance to the other person; the imagination of his or her judgment of that appearance; and some sort of self-feeling, such as pride or mortification in return. The imagined judgment is quite essential. We often imagine, and in imagining, share the judgments of the other mind (Cooley, 1902).

These practices were reported by most of the participants. Amber, for instance, stated the following when asked how she thought people saw her prior to her implants:

I know that I'm better than the average person you see shopping at Wal-Mart, but not as good as the girl shopping at Abercrombie. You know, it's all relative. I think I'm really cute for a mom, but if I had to go on a date or something, I'd be really worried.

Carol explains what she thinks others think of her appearance:

I'm thinking they are probably thinking I still have a really flat chest...

Kim's imagination comes to life in the following excerpt:

I would just think, oh gosh, next to somebody else I would say, "Wow-it'd be nice to have my body look like that in a bathing suit”. Just like, "That sucks! That's not fair! I got the short end of the stick genetically!” You think people don't like the way you look or they look at you and say stuff about you...

As a result of these imaginary judgments, according to Cooley, in the end one experiences some sort of self-feeling, such as pride or mortification.

Jennifer feels proud now that she has had augmentation surgery:

I'm confident in what I wear. I don't lack confidence because of my chest anymore. I don't let my lack of confidence hold me back anymore.

George Herbert Mead's imaginative role-play helps us understand how the daughters "me" emerged and then engaged in role-play practices prior to implants. They went through a rehearsal process with an imaginary self that created having the perfect breasts. For instance, Annie's behavior reflects Mead's theory of identifying her "me" through social interaction:

I guess seeing pictures of other girls who have boobs in magazines, I just wanted them. The way they look right here (she touches her breast bone), cleavage, I like that.

Annie, after she had interacted with people over time (pictures of other girls in magazines) saw herself as less than those women depicted.

In another case, as shown in the comment below, Jane, talking about her surgery went through a role-playing process.

I went in and showed them pictures of what I wanted, what I didn't want, you know. I did not want to be too big, that was my biggest thing. I wanted to look natural. And so I took pictures in and he (the surgeon) gave me some implants to wear underneath my shirt to see how I liked the size. He gave me a $375 \mathrm{cc}$, which is like 375 tablespoons and that, was pretty much the equivalent to a full $\mathrm{C}$ cup. And I liked that one, I thought it was great, so we were gonna go with that.

The women altered their real self that they learned not to like through social interaction, and through role-play they imagined having larger breasts in various situations and ultimately liked that better. In some cases, their role-playing techniques allowed them to transition smoothly from practicing with breasts to actually having them.
Another trend inductively discovered in the data was how the participants of the study use implant to construct gender. The following section focuses on the social construction of reality paradigm to examine the efforts made by both mothers and daughters prior to surgery in order to construct gender. The mothers often referred to their daughters in a pre-surgery state as though they had something physically wrong with them. They were not whole, missing something, immature, not feminine, and they looked like "boys". Sammie explained why she thought her daughter's flat breasts kept her from dating:

Susan wasn't dating; the guys were all her friends, just her friends. So at some point you have to wonder if they just stay friends all the time because she was flat chested like one of them. At what point does she get to become a young lady? Which is sad to say but it's almost like if she doesn't have boobs then the guys would never see her as more than just a buddy which is what she was.

Not only were the mothers influenced by the social construction of gender, but the daughters as well. The daughters willingly underwent elective surgery in order to obtain larger breasts, those that would be clearly identified as womanly, separate and distinct from manly. Through the portrayal of the daughter's surgical narratives, one can see how the young women actively took part in "doing gender". As illustrated in the following comments, many of the subjects talked about altering their boyish image, becoming more beautiful and feminine.

Jennifer, describing how she asked her parents for augmentation for graduation, stated:

It came down like I told him (her father). I was flat like an 8 year old boy. And it's not something that bothered him, it bothered me. To the point that I was wearing two padded bras when I was in middle school.

Although another respondent, Jane, didn't specifically say she looked like a boy, the social construction of what a woman should look like taught her she was deficient:

I was not happy with how I looked. I wasn't comfortable. I didn't feel like a woman. I felt like a thirteen year old girl and they (breasts) weren't gonna get any bigger. And I was not comfortable, I was not comfortable at all. I dunno, I just wasn't comfortable. When you are so small, it doesn't make you feel like a woman.

Sheryl described how she didn't feel beautiful prior to surgery, but talking about her post-surgery image stated:

I am able now to look in the mirror and say you know, I am a pretty girl! I am a beautiful girl. I can say that. I used to not be able to say that.

Social construction of reality theory clearly weaves through the comments above. The women underwent augmentation surgery to appear as feminine, grown women. The daughters, maintaining the gender order, became society's constructed definition of "woman" after surgery.

Reference group theory explains how the women in this study use others as yardsticks to evaluate their own beauty. In each of the narratives, the women made realistic comparisons using relatives or friends and idealistic comparisons using media icons. Each of the daughters described the reference groups that played a role in their decision to undergo breast augmentation. These reference groups included coworkers, close friends, and fellow sorority sisters. Sheryl used her coworkers as a "yard-stick", comparing her breasts to those of the women she worked with: 
A couple of girls I've worked with, actually there were 2 girls there that had boob jobs. And then my boss did. They talked about how I would like it (breast augmentation) and I would be happy. They gave me advice.

Also, some participants created a mental image of what their friends look like physically and compared themselves to these friends. For instance, Annie describing her experiences with her peers since junior high commented:

Uh, well it's been going on like, since I was in junior-high. When am I gonna get boobs? ... Oh, like, how the girls have been developing and I haven't. Like when you wear a sports bra and go and change, I didn't have anything.

In other cases, the respondents described their sorority sisters and how breast augmentation was popular within the sorority house. The respondents recognized that breast augmentation was common within this reference group, something one has done if "needed". Jane described how augmentation seemed common among all the girls she was around:

All the people that I was around, I felt like it (breast augmentation) was socially acceptable. It wasn't really like, “Oh my God-you're gonna get that done?” I think everybody who had to get it done would have done it.

Reference group theory allows for an understanding of how the women in this study took note of their close friend's body structure, weight, and breast size. Using friends as a tool for comparing how they themselves ranked, many girls acknowledged that their bodies were not as attractive as their friend's. Those in the study who belonged to sororities came to view breast augmentation as common, regular, and "no big deal".

Veblen's conspicuous consumption theory (1899) can explain the behaviors and practices of the participants. As Veblen described in his theory, rich people who display their wealth often receive acknowledgement. When something is valued, those who can afford it often purchase it. All of the women in this study belonged to what may be defined as a "modern day wanna be leisure class". The average value of their homes was $\$ 159,321$. Some drove luxury vehicles such as Lexus, BMW, and Mercedes; others drove SUVs and Sedans. The parents paid an average of \$1,441.00 per month towards the daughters living expenses. This leisure status afforded the parents to pay for not only their daughters' living expenses, but their breast augmentation surgery as well.

Kim describes why women feel large breasts give them desired status:

...I would think the media, I mean it's just so, so like stereotypical of what a perfect woman is. You know, big boobs, really skinny, looks like specific celebrities, models and everything. It's about diets, no carbs, no this and that. You know, everything in a magazine, everything on TV, you know everyone is beautiful. I mean if everybody was fat and had no boobs then I probably wouldn't have wanted them, but if that's the way we grew up, the society you grow up in, you want to look a specific way. Like you would like to have a small waist with a bigger chest. I mean I'm sure that's our American culture in general.

Amber's description of Angelina Jolie brings to focus a description of this American standard of beauty:

I like Angelina because I think she is the most beautiful woman. She's Amazon tall, gorgeous hair, and big lips. Looks like she just crawled out of bed and had every hair fall perfectly into this mess of dreaminess. And she has kids hanging all over her. She lets the rest of us know how bad we suck.
Further, those women who augment their breasts may "flash" them to others as the ultimate display of conspicuous consumption.

Linda describes how the attainment of larger breasts has brought her daughter, Kim, esteem and admiration by men especially:

She has on occasion gone places with me, with like the little spaghetti strap top that she really shouldn't have been wearing. We were in a restaurant once and men just kept ogling her. We were in the grocery store once and the same thing. There were these firefighters that were trying to see over the aisle and look at her...

It is important to note here that Kim isn't wearing the spaghetti strap innocently, she wants to make sure her breasts are visible, admired, and can enhance her status. The flashing of breasts demonstrates that their chests are augmented and they can afford to buy them.

\section{Discussion}

This research sociologically explored the lives of twenty women who either gifted or received breast implants for graduation. First, symbolic interaction illuminated why most of the daughters in the narratives "faked" the appearance of large breasts prior to implant surgery through the use of heavy cotton padding, water bras, or multiple bras. All of these women made extreme efforts in the backstage to conceal what they really were and manage how they appeared in the front stage, in order to create the feminine impression desired. The daughter's narratives supported both Cooley's practice of reflective judgment and Mead's role-playing techniques. All of the daughters in this study practiced having larger breasts before undergoing surgery, and considered the procedure a success when audience members couldn't tell they had surgery.

The social construction of reality paradigm offered a means to analyze the efforts taken to construct gender by examining how both mothers and daughters actively engaged in the perpetuation of the construction of gender. The mothers often referred to their flat-chested daughters in a pre-surgery state as though they were physically marred. They were not whole, missing something, immature, not feminine, and they looked like "boys". The daughters also wanted to undergo breast augmentation surgery in order to obtain larger breasts, those that would be clearly identified as womanly, separate and distinct from manly.

Reference group theory provided a means to explain ways in which women compared themselves to friends and often to those they consider more beautiful than themselves. The perception of the actual self in relation to the ideal one resulted in a sense of failure. Therefore, the daughters proceeded with implants in order to look like their reference group members.

As conspicuous consumption theory explained, when the level of consumption necessary to be conspicuous becomes more readily available, people want to demonstrate that they have a high quality of life. All of the women in this study belonged to the middle class or what may be defined as a modern day leisure class. This leisure status afforded them the ability to pay for not only their daughter's living expenses, but their breast augmentation as well.

It is important to report that most of the daughters and mothers were very clear that the decision to undergo breast implant surgery occurred at a young age. Critical events leading to sur- 
gery included encounters with ill-fitting clothing and the wish to be supplied with a generous gift for graduating from highschool. The gifting of breast implants for high-school graduation often took place because the daughter finally reached age 18 , the age at which most surgeons first allow the surgery.

This study shows that gifting and receiving implants for graduation is primarily motivated by both personal feelings of physical inadequacy and sociocultural representation of beauty. In fact, the majority of respondents expressed complete comfort with their gifting and receiving of breast implants for graduation, claiming it was a great decision. Most said they had never experienced such comfort in clothing, self-confidence, and that they would do it again if necessary. Additionally, most of the mothers agreed surgery was worth any risk to increase their daughter's confidence.

\section{REFERENCES}

American Society for Aesthetic Plastic Surgery Inc. (2004). Top 5 female cosmetic procedures. URL (last checked 30 March 2008) http://www.plasticsurgery.org/media/statistics/loader.cfm?url=/com monspot/security/getfile.cfm\&PageID=16734

Austin, A. (2000). More teens opt for plastic surgery. Christian Science Monitor, 92, 14.

Berger, P., \& Luckmann, T. (1966). The social construction of reality: A treatise in the sociology of knowledge. New York: Doubleday Dell. Beyond, B. (2003). Beyond botox. Economist, 369, 61-62.

Blumer, H. (1969). Symbolic interactionism: Perspective and methods. Englewood Cliffs, NJ: Prentice Hall.

Bulik, C., \& Kendler, K. (2000). I am what I (don't) eat: Establishing an identity independent of an eating disorder. American Journal of Psychiatry, 157, 1755-1760. doi:10.1176/appi.ajp.157.11.1755

Carolan, M. (2005). The conspicuous body: Capitalism, consumerism, class and consumption. Worldviews, 9, 82-111. doi:10.1163/1568535053628436

Chase, S. (1995). Ambiguous empowerment: The work of narratives of women school superintendents. Amherst: University of Massachusetts Press.

Cooley, C. H. (1964). Human nature and the social order. New York: Charles Scribner's Sons.

Davis, K. (2003). Dubious equalities and embodies differences: Cultural studies on cosmetic surgery. Lanham, MD: Rowman and Littlefield.

Dawson, E., \& Chatman, E. (2001). Reference group theory with implications for information studies: A theoretical essay. Information Research, 6, 1-26.

DeNoon, D. (2003). Latest plastic surgery trends and stats: His/hers, mom/daughter surgery new trend. Web MDHealth Medical News. URL (last checked 17 January 2007).

http://www.webmd.com/skin-problems-and-treatments/news/200306 05/latest-plasticsurgery-trends-stats

Didie, E., \& Sarwer, D. (2003). Factors that influence the decision to undergo cosmetic breast augmentation surgery. Journal of Women's Health, 12, 241-254. doi:10.1089/154099903321667582

Farrell, J. (2004). More teens see implants as a right. Miami Herald. InfoTrac Newspapers database. URL (last checked 10 July 2005).

Ferber, A. (2000). A comment on Aguirre: Taking narrative seriously. Sociological Perspectives, 43, 341-349.

Goffman, E. (1959). The presentation of self in everyday life. New York: Doubleday.

Harrison, K. (2003). Television viewers' ideal body proportions: The case of the curvaceously thin woman. Sex Roles, 48, 255-265. doi:10.1023/A:1022825421647

Hinchman, L., \& Hinchman, S. (1997). Introduction. In L. P. Hinchman, \& S. K. Hinchman (Eds.), Memory, identity, community: The idea of narrative in the human sciences (pp. 13-30). New York: State University of New York Press.

Holzgang, J. (2000). Body image project: Facts on body and image.
URL (last checked 6 November 2006)

http://www.justthink.org/bipfact.html

Hyman, H., \& Singer, E. (1968). Readings in reference group theory and research. New York: Macmillan.

Kelley, R. (2003). Giving the gift of rhinoplasty. Newsweek, 142, 76.

Kilbourne, J. (1994). Still killing us softly: Advertising and the obsession with thinness. New York: Guilford Press.

LaVoie, A. (2000). Media influences on teens: Facts compiled by Allison LaVoie. URL (last checked 13 April 2000).

http://kidsnrg.simplenet.com/grit.dev/london/g2_jan12/green_ladies/ media/

Lorber, J. (1994). Paradoxes of gender. New Haven, CT: Yale University Press.

McKenzie, J. (2006). New grad gift: Breast implants. Mind \& Body, 5, 15-18.

Mead, G. (1934). Mind, self, and society. Chicago: University of Chicago Press.

Mishler, E. (1995). A matter of time: When, since, after Labov and Waletzky. Journal of Narrative and Life History, 7, 69-73.

Moberg, M., Siskin, J., Stern, B., \& Wu, R. (1999). Sara Lee: Wonderbra. URL (last checked 6 July 2005) http://wwwpersonal.umich.edu/ afuah/cases/case15.html

More girls getting implants (2004). The New York Post (pp. 1-8). Retrieved July 19, 2006, from InfoTrac Newspapers database.

Orbach, S. (1993). Hunger strike: The anorectic's struggle as a metaphor for our age. London: Penguin.

Patton, T. (2006). Hey girl, am I more than my hair?: African American women and their struggles with beauty, body image, and hair. NWSA Journal, 18, 24-51. doi:10.2979/NWS.2006.18.2.24

Rabak-Wagener, J., Eickhoff, S., \& Vance, K. (1998). The effect of media analysis on attitudes and behaviors regarding body image among college students. Journal of American College Health, 47, 29-36. doi:10.1080/07448489809595616

Rauste-von Wright, M. (1989). Body image satisfaction in adolescent girls and boys: A longitudinal study. Journal of Youth and Adolescence, 18, 71-83. doi:10.1007/BF02139247

Sarwer, D., Magee, L., \& Clark, V. (2004). Physical appearance and cosmetic medical treatments: Physiological and socio-cultural influences. Journal of Cosmetic Dermatology, 2, 29-39. doi:10.1111/j.1473-2130.2003.00003.x

Schor, J. (1998). Keeping up with the Trumps: How the middle class identifies with the rich-Excerpt from "the overspent American: Upscaling, downshifting, and the new consumer”. URL (last checked 9 September 2005).

http://findarticles.com/p/articles/mi_m1316/is_n7-8_v30/ai_2098784 0

Shrum, L., Burroughs, J., \& Rindfleisch, A. (2005). Television’s cultivation of material values. Journal of Consumer Research, 32, 473-479. doi:10.1086/497559

Sile, V. (1981). Body and social constructionism: Formation of individuality in the process of socialization. Unpublished Doctoral Dissertation, Vilnius: Vilnius State University.

Synnott, A. (1989). Truth and goodness, mirrors and masks—Part I: A sociology of beauty and the face. British Journal of Sociology, 40, 607-637. doi:10.2307/590891

Thomas, W. I. (1923). The unadjusted girl. Boston: Little Brown.

Veblen, T. (1899). The theory of the leisure class. London: Allen \& Unwin.

Weitz, R. (1999). The politics of women's bodies: Sexuality, appearance, and behavior. Teaching Sociology, 27, 429-431. doi: $10.2307 / 1319054$

West, C., \& Zimmerman, D. (1987). Doing gender. Gender and Society, 1, 125-151. doi:10.1177/0891243287001002002

Why are parents buying their girls the gift of surgery? (2005). [News broadcast transcript]. In 20/20 (Producer), ABC news. New York: ABC. URL (last checked 27 December 2011). http://abcnews.go.com/2020/story?id=875821

Zukin, S., \& Maguire, J. (2004). Consumers and consumption. Annual Review of Sociology, 30, 173-197. doi:10.1146/annurev.soc.30.012703.110553 